\title{
Requerimiento hidrico $y$ areas sujetas a riego en Espinar: estimaciones
}

\section{Water requirement and areas subject to irrigation in Espinar: estimates.}

Juan E. Gil ${ }^{1}$

Recibido: 21 de Abril del 2021 | Aceptado: 01 de Junio del 2021

\author{
${ }^{1}$ M. Sc. en Ciencia y Tecnología Ambiental. Docente cesante de la Facultad de Ciencias Biológicas, Área \\ de Ecología. Consultor en temas de Gestión Ambiental. \\ Correo electrónico:mundoandino2005@yahoo.es
}

\section{Resumen}

Espinar constituye uno de los escenarios más importantes en los aspectos pecuario, agrícola, piscícola y turismo; la planicie andina posee pasturas naturales y suelos ricos en humus, los que son una muestra del potencial uso que se podría dar a estos recursos naturales. La pradera andina en Espinar es equivalente a 300,000 hectáreas, éstas podrían ser más productivas si se incorporaran tecnologías de riego, mejoramiento de pastos y ganado, uso del agua en piscicultura, principalmente truchicultura. El principal colector es el río Apurimac y sus tributarios que surcan el territorio con excelentes caudales en época de precipitación y evidencian caudales críticos en temporada de secas y conducen a través de sus cauces el recurso hídrico que podría ser empleado para el despegue socio-económico y ambiental de los pobladores de Espinar que pertenece a la región Cusco. Las estimaciones sobre demanda del recurso hídrico, han sido efectuadas empleando metodologías convencionales para los diversos usos del agua, vinculados a la irrigación de pasturas, empleo en ganadería de camélidos sudamericanos, ovinos, vacunos y en truchicultura; los cálculos han sido determinados en base a información primaria y a la experiencia desarrollada durante los últimos años en el ámbito de estudio, que está referido a la superficie de directa influencia del río Apurimac. Las estimaciones se vinculan a los usos del agua para consumo humano, irrigación en agricultura y de pasturas, actividades pecuarias, piscicultura y, caudal ecológico; siendo la demanda hídrica calculada de $48.8 \mathrm{~m}^{3} / \mathrm{s}$ requeridos para irrigar 45,421 ha.

Palabras clave: Caudal; demanda hídrica, pradera andina, uso consuntivo.

\begin{abstract}
Espinar constitutes one of the most important scenarios in the livestock, agricultural, fish farming and tourism aspects; the large Andean plateau has natural pastures and soils rich in humus, which are an example of the potential use that could be given to these natural resources. The Andean
\end{abstract}


prairie in Espinar is equivalent to 300,000 hectares, these could be more productive if irrigation technologies, improvement of pastures and livestock, use of water in fish farming, mainly trout farming, were incorporated. The main collector is the Apurimac River and its tributaries that cross the territory with excellent flows in the rainy season and show critical flows in the dry season and lead through its channels the water resource that could be used for socio-economic and environmental take-off of the inhabitants of Espinar province that belongs to the Cusco region. Estimates of the demand for water resources have been made using conventional methodologies for the various uses of water, linked to pasture irrigation, employment of South American camelidaes, sheep, cattle and trout farming; the calculations have been determined based on primary information and the experience developed in recent years in the field of study, which refers to the area of direct influence of the Apurimac River. The estimates are linked to the uses of water for human consumption, irrigation in agriculture and pastures, livestock activities, fish farming and, ecological flow; being the calculated water demand of $48.8 \mathrm{~m}^{3} / \mathrm{s}$ required to irrigate 45,421 ha.

Keywords: Andean grassland; consumptive use, flow, water demand.

\section{Introducción}

\section{Ámbito de estudio}

La zona de análisis y estimaciones se ubica en la provincia de Espinar, Cusco, la que tiene una extensión de aproximadamente $5,200 \mathrm{~km}^{2}$, se halla ubicada en una zona con un clima relativamente frígido, sus temperaturas medias oscilan entre -18.6 y $17.2 \quad{ }^{\circ} \mathrm{C}$. La altitud del ámbito de estudio se localiza sobre los 4,000 msnm (SENAMHI, 2010).

El principal colector de aguas de escorrentía, escurrimiento proveniente de humedales y derretimientos glaciares es el río Apurimac e involucra las cuencas de los ríos Hornillos, en territorio de la región Arequipa y los afluentes Suykutambo, Cerritambo, Sañu, Huayllumayu, Cañipía, Quero y Salado, en territorio de la provincia de Espinar, conforme se muestra en la figura 1 .

Figura 1. Ámbito de estudio para las determinaciones de demanda hídrica.

\section{Características ambientales en la planicie de espinar}

La pradera andina en el ámbito de estudio posee peculiaridades singulares en cuanto a factores climáticos; es el caso que las temperaturas medias anuales oscilan entre $16.3{ }^{\circ} \mathrm{C}$ y $-4.46{ }^{\circ} \mathrm{C}$ (SENAMHI, 2010), siendo los meses más fríos junio, julio y agosto, en los que se producen las heladas más intensas. En las partes altas de la provincia son comunes las nevadas aun en la estación seca. 
SENAMHI, en el Boletín Climático Nacional (2010), señala que la evapotranspiración en la planicie de Espinar, puede alcanzar valores de 1,183.2 $\mathrm{mm}$; la variación de la evapotranspiración a lo largo del año muestra una cierta regularidad, la falta de agua en el suelo en los meses de estiaje, está determinado porque los valores de evapotranspiración superan ampliamente a los valores de precipitación de la provincia $(775.8 \mathrm{~mm})$. Por lo tanto, el requerimiento hídrico por la vegetación es mayor en estos meses de escasa precipitación y alta evapotranspiración.

En lo referente a los suelos; de acuerdo a la clasificación de los suelos por su capacidad de uso mayor (MINAGRI, 2009), se ha identificado los siguientes grupos y clases, P1 (4.2\%); P2 (22.82\%); P3 (25.23\%); por tanto, los suelos más representativos del ámbito de análisis tienen aptitud para la producción de pastos, que abarca el $52.25 \%$ del área total.

Tabla 2. Clasificación de tierras por su capacidad de uso mayor en Espinar

Según estudios del MINAGRI (2009), el uso actual que se le da a las tierras en los distritos de Suykutambo, Coporaque y Espinar, que conforman el ámbito de estudio, están representadas por áreas de pastoreo que ocupan el 83.99\%, seguido por las áreas de cultivo con el $9.04 \%$ y otros usos con el $6.97 \%$. Ecológicamente, en el ámbito de estudio sobresale la Zona de Vida Natural Páramo muy húmedo Subalpino Subtropical, la cual cubre más del 51\% del territorio, por lo que el territorio presenta condiciones climáticas, edáficas, topográficas y con una cobertura vegetal que posibilita el desarrollo de la actividad pecuaria. La vegetación predominante está formada por asociaciones de poáceas que junto al césped de puna soportan una importante población pecuaria (ovinos, vacunos, camélidos sudamericanos, equinos y otros). Más del $70 \%$ de las asociaciones están integradas por Festuca dolycophylla, Festuca heterophylla, Calamagrostis intermedia, Calamagrostis vincugnarum; stipa ichu, Stipa obtusa, Distichlis humilis, Bromus sp. Achemilla pinnata, Poa gymnatha, y otros (Florez, 2005). Todas estas especies altamente palatables al ganado y que requieren altas concentraciones de humedad provenientes de la precipitación pluvial. El objetivo del trabajo ha sido la estimación del requerimiento hídrico para actividades consuntivas y no consuntivas en el ámbito de influencia directa de la cuenca alta del río Apurimac y tributarios entre Angostura y la confluencia con el río Salado. Este objetivo, como se señala, implica que el uso consuntivo es aquel en el que el agua, una vez usada, no se devuelve al medio donde se ha captado, ni de la misma manera que se ha extraído. El ejemplo más claro es el de la agricultura, ya que deriva agua por el riego que después se pierde por la evapotranspiración (el $80 \%$ del total) y, por tanto, no se incorpora de forma líquida al ciclo del agua, sino en forma de vapor a la atmósfera; de otro lado, el uso no consuntivo, es cuando el agua que se utiliza es devuelta posteriormente al medio del cual ha sido extraída, aunque no al mismo lugar. A pesar de todo, esta agua puede presentar diversas alteraciones fisicoquímicas y biológicas en función del uso que se le haya dado (Bernex et al, s/f). Lo anterior, está tipificado en el Reglamento de la Ley 293338 (MINAGRI, 2010), que señala como uso poblacional y productivo del agua, indicando que el orden de preferencia en 
el uso productivo es: Agrario, acuícola y pesquero; energético, industrial, medicinal y minero; recreativo, turístico y transporte y; otros usos. Éste es el marco de referencia utilizado para las estimaciones de las demandas en el ámbito de estudio.

\section{Metodología}

De conformidad a la FAO (2011), las precipitaciones, y en concreto su fracción efectiva, aportan parte del agua que los cultivos necesitan para satisfacer sus necesidades de transpiración. El suelo actúa como reserva, almacenando parte del agua de las precipitaciones y devolviéndosela a los cultivos en momentos de déficit o escasez. En climas secos, o durante periodos secos prolongados, el riego es necesario para compensar el déficit de evapotranspiración (transpiración del cultivo y evaporación del suelo) producido por unas precipitaciones erráticas o insuficientes (Aguilera et al, 1996). De otro lado, el uso consuntivo del agua de riego se define como el volumen de agua necesario para compensar el déficit entre la evapotranspiración potencial y la precipitación efectiva durante la época de crecimiento del cultivo, por un lado, y los cambios en el contenido de humedad del suelo por otro (Piñas, 2009). Esto varía considerablemente con las condiciones climáticas, las estaciones, los cultivos y el tipo de suelo.

En el caso de las necesidades de riego, referidas a la cantidad de agua y al momento de su aplicación, a fin de compensar el déficit de humedad del suelo durante un periodo vegetativo; se determinan utilizando la evapotranspiración del cultivo en consideración (ETc) menos el agua aportada por las precipitaciones (Blaney et al, 1950; Ortiz et al, 2018). Cuando la precipitación efectiva es mayor que las necesidades de riego, la demanda o riego bruto es igual a cero (0). En caso contrario, cuando la precipitación efectiva es menor al uso consuntivo del cultivo, la demanda se define por la diferencia entre la ETc y el agua que se aporta por precipitación (Doorenbos et al, 1982).

Para el estudio se utilizaron registros de precipitación $(\mathrm{mm})$, humedad relativa y temperatura media $\left({ }^{\circ} \mathrm{C}\right)$ de más de 30 años a escala mensual (1972-2006), obtenidos de la estación meteorológica de Angostura y, la información de solaridad, dirección predominante y velocidad del viento, proporcionada por la estación meteorológica de Yauri (Espinar).

Para la estimación de la evapotranspiración de cultivo y pasturas, se utilizó la denominada condiciones estándar (ETc), y se refiere a la evapotranspiración de cualquier cultivo y parcelas de pasturas, cuando se desarrollan en parcelas amplias, bajo óptimas condiciones de suelo y agua de acuerdo a las condiciones climáticas reinantes. El método aplicado para la estimación de la evapotranspiración es el método Penman (1963)-Monteith $(1965,1985)$ de la FAO (1990).

Se trabajó con datos de radiación solar diaria, temperatura máxima, temperatura mínima, humedad relativa máxima, humedad relativa mínima y velocidad de viento, para estimar la evapotranspiración de referencia, se utilizó la siguiente ecuación, que fue revisada por el ASCE (American Society of Civil Engineers), (Walter et al., 2005). 
$\mathrm{ET}_{\mathrm{o}}=\frac{0,408 \Delta\left(\mathrm{R}_{\mathrm{n}}-\mathrm{G}\right)+\gamma \frac{900}{\mathrm{~T}+273} \mathrm{u}_{2}\left(\mathrm{e}_{\mathrm{s}}-\mathrm{e}_{\mathrm{a}}\right)}{\Delta+\gamma\left(1+0,34 \mathrm{u}_{2}\right)}$

Donde:

$\mathrm{ET}_{\mathrm{o}}=$ Evapotranspiración de referencia $\left(\mathrm{mm} \mathrm{día}^{-1}\right)$.

$\mathrm{R}_{\mathrm{n}}=$ Radiación neta en la superficie del cultivo $\left(\mathrm{MJ} \mathrm{m}^{-2}\right.$ día $\left.^{-1}\right)$.

$\mathrm{G}=$ flujo del calor de suelo $\left(\mathrm{MJ} \mathrm{m}^{-2} \mathrm{dí}^{-1}\right)$.

$\mathrm{T}=$ Temperatura media del aire a $2 \mathrm{~m}$ de altura $\left({ }^{\circ} \mathrm{C}\right)$.

$\mathrm{u} 2=$ velocidad del viento a $2 \mathrm{~m}$ de altura $\left(\mathrm{m} \mathrm{s}^{-1}\right)$.

$\mathrm{e}_{\mathrm{s}}=$ Presión de vapor de saturación $(\mathrm{kPa})$.

$\mathrm{e}_{\mathrm{a}}=$ Presión real de vapor $(\mathrm{kPa})$.

$(e s-e a)=$ Déficit de presión de vapor $(\mathrm{kPa})$.

$\Delta=$ pendiente de la curva de presión de vapor $\left(\mathrm{kPa}^{\circ} \mathrm{C}^{-1}\right)$.

$\gamma=$ constante psicrométrica $\left(\mathrm{kPa}^{\circ} \mathrm{C}^{-1}\right)$.

La evapotranspiración de referencia (ETo), es la tasa de evapotranspiración de un cultivo extenso y uniforme de gramíneas en crecimiento activo $(8 \mathrm{a} 15 \mathrm{~cm}$ de altura) y que cubre totalmente el suelo y no está escaso de agua. Según Allen, Pereira, Raes, \& Smith, (2006), es una medida relacionada con el clima que expresa el poder evaporante de la atmósfera; este concepto se introdujo para estudiar la demanda de evapotranspiración de la atmósfera, independientemente del tipo y desarrollo del cultivo y de las prácticas de manejo; los únicos factores que afectan la ETo, son los parámetros climáticos. La evapotranspiración de referencia refleja la verdadera necesidad de agua para los cultivos que deben desarrollarse en condiciones óptimas de humedad. Para calcular la ETo, se recomienda que en aquellas zonas en las que se disponga de datos medidos sobre la temperatura, la humedad, el viento y las horas de radiación, se utilice el método o ecuación de Penman-Monteith, ya que se considera que proporciona resultados más satisfactorios para predecir los efectos del clima sobre las necesidades de agua de los cultivos (Fuentes, 2003).

Además, se calculó la evapotranspiración potencial (ETP), expresada en mm/mes; considerando las recomendaciones hechas por Hargreaves (1985), y utilizando la información meteorológica, (Milla, 2015), empleando la siguiente ecuación:

\section{$E T P=M F * T M F * C H * C E$}

Donde:

ETP: Evapotranspiración Potencial en $\mathrm{mm} / \mathrm{mes}$.

MF: Coeficiente mensual de evapotranspiración que se encuentra en función de la latitud.

H: Altitud promedio de la zona de cultivos en m.s.n.m.

$\mathrm{CH}$ : Factor de corrección por humedad relativa del aire, cuando la humedad relativa es menor de $64 \%$ se asume $\mathrm{CH}=1.00$

HR: Humedad relativa mensual expresada en $\%$. 
CH: Factor de corrección por elevación (altitud).

$\mathrm{CE}=(1+0.04) * \mathrm{H} / 2000$

$\mathrm{CH}=0.166 *(100-\mathrm{HR})^{0.5}$

Según Allen et al (2006), la demanda hídrica es igual al volumen total de agua extraída. Este volumen de agua extraído es igual a los consumos más el agua extraída no consumida. Bajo esta delimitación en función de la demanda, la extracción es definida en sus componentes de la siguiente manera:

$\mathbf{D h}=\sum \mathbf{U}$

Donde

Dh: demanda hídrica;

U: uso sectorial, doméstico y ecosistemas

$\mathrm{Dh}=\sum \mathbf{c}+$ Aenc

Donde

Dh: demanda hídrica;

c: consumo sectorial, doméstico y de ecosistemas,

Aenc: agua extraída no consumida sectorial y doméstico.

\section{$\mathrm{Dh}=\mathrm{Ch}+\mathrm{Csp}+\mathrm{Csm}+\mathrm{Css}+\mathrm{Cea}+\mathrm{Ce}+\mathrm{Ca}+\mathrm{Aenc}$}

Donde

Dh: demanda hídrica;

Ch: consumo humano o doméstico;

Csp: consumo del sector primario;

Csm: consumo del sector manufacturero

Css: consumo del sector servicios;

Cea: caudal ecológico y ambiental;

Ce: consumo del sector energía (hidroeléctrica y termoeléctrica);

Ca: consumo del sector acuícola;

Aenc: agua extraída no consumida

La inclusión de la demanda hídrica asociada a la generación de energía y a la producción acuícola, clasificados como usos no consuntivos, toma como referencia el volumen de agua aprovechado en un año base, siendo este una variable de stock y no de flujo.

Entre los principales métodos teóricos que se utilizan para la determinación del coeficiente de uso consuntivo y que fueron consultados, tenemos:

- $\quad$ Método de Blanney Criddle (1950).

- $\quad$ Método de Penman. (FAO, 1990)

- $\quad$ Método de Hargreaves et al (1985).

- Método de Thornthwaite (1948).

Estos métodos se refieren a las condiciones climáticas, agronómicas y edáficas propios de una zona dada. Los coeficientes de Uso consuntivo (Kc), 
son datos muy valiosos que se usan para determinar la posible área de riego, de un proyecto, de una finca, etc. sobre la base de un volumen disponible de agua. Sus aplicaciones son múltiples, y se listan a continuación:

1. Permite elaborar calendarios de riego para los cultivos, fijar láminas e intervalos de riego en función de la eficiencia de riego. Esto permite apoyar la planificación de cultivos y riegos por cultivos (FAO, 2006).

2. En el caso de agua de riego con alto contenido de sales en solución, el uso consuntivo permite determinar las láminas de sobre riego, necesarias para prevenir problemas de salinización de los suelos (Martínez, 1991).

3. Estimar los volúmenes adicionales de agua que serán necesarios aplicar a los cultivos en el caso que la lluvia no aporte la cantidad suficiente de agua.

4. Determinar en grandes áreas (cuencas) los posibles volúmenes de agua en exceso a drenar.

5. Determinar en forma general la eficiencia con la que se está aprovechando el agua y por lo mismo, planificar debidamente el mejoramiento y superación de todo el conjunto de elementos que intervienen en el desarrollo de un distrito de riego (Garay,2009).

Para la estimación de la demanda hídrica con fines de riego se definió la precipitación al $75 \%$ de persistencia o probabilidad. Para la frecuencia o probabilidad de ocurrencia, se usó la fórmula de Weibull, (García, E.,2009).

$$
f=\frac{m}{N+1}
$$

Donde:

f: Frecuencia o probabilidad de ocurrencia $\mathrm{m}$ : Valor de posición de la lluvia ordenada en forma decreciente.

$\mathrm{N}$ : Número total de valores de precipitación mensual. La precipitación efectiva es la cantidad neta de agua utilizada por las plantas. Se estimó por el método de WPRS-USA-Water Power Resources Service (citado por FAO, 2006) teniendo en cuenta la precipitación al $75 \%$ de persistencia a la zona a irrigar.

Se calculó el Kc ponderado. Es el promedio de Kc ponderado en el área de siembra, se calculó utilizando la siguiente expresión:

$$
\text { Kcponderado }=\frac{\Sigma(A * K c)}{\Sigma A}
$$

Se determinó la evapotranspiración real o del cultivo, expresada en ( $\mathrm{mm} / \mathrm{mes})$ :

$\mathbf{E T c}=\mathbf{E T P} * \mathrm{Kc}$

Donde:

ETc: Evapotranspiración del cultivo ( $\mathrm{mm} / \mathrm{mes})$.

ETP: Evapotranspiración potencial ( $\mathrm{mm} / \mathrm{mes})$.

Kc: Coeficiente de cultivo ponderado. 
Luego se determinó el requerimiento neto de agua o demanda unitaria $(\mathrm{mm} / \mathrm{mes})$ que es la lámina adicional de agua que se debe aplicar a un cultivo para que supla sus necesidades.

\section{Req $=$ ETc - P.Efec.}

Donde:

Req: Requerimiento neto de agua.

ETc: Evapotranspiración del cultivo ( $\mathrm{mm} / \mathrm{mes})$.

P. Efec: Precipitación efectiva ( $\mathrm{mm} / \mathrm{mes})$.

Se determinó el volumen de requerimiento neto de agua por hectárea $\left(\mathrm{m}^{3} / \mathrm{ha}\right)$. Para convertir en $\mathrm{m}^{3} /$ ha, se multiplica por 10 .

\section{Req Vol. $=$ Req $* 10$}

Se estimó un $35 \%$ de eficiencia de riego (Ef. Riego), debido al riego por inundación que presenta el ámbito de estudio.

Se determinó el requerimiento volumétrico bruto de agua $\left(\mathrm{m}^{3} / \mathrm{ha}\right)$.

$$
\text { Req Vol bruto }=\frac{\text { Req Vol }}{\text { Ef.riego }}
$$

El módulo de riego es la demanda de agua. Se determinó con la siguiente fórmula:

$$
M R=\left(\frac{1000}{3,600 * N^{\circ} \text { de días mes } * N^{\circ} \text { horas riego }}\right)
$$

Donde:

MR: Módulo de riego (1/s/ha).

Req. Vol. Bruto: Requerimiento volumétrico bruto de agua ( $\left.\mathrm{m}^{3} / \mathrm{ha}\right)$.

Se obtuvo el caudal requerido ( $Q$ requerido), expresado en 1/s. Es el caudal requerido por el sistema.

Para la determinación del caudal ecológico, se utilizó lo especificado por la ANA (2016) y en la Resolución Jefatural $\mathrm{N}^{\circ}$ 267-2019-ANA, contemplando las particularidades del curso de agua y las necesidades de agua del ecosistema y de los usuarios del agua (art. 4) y lo dispuesto por el Anexo II aplicando el método de simulación de hábitat u holístico.

En el marco de la Resolución Jefatural mencionada, las determinaciones del caudal ecológico se sustentaron en las características físicas y biológicas del cauce natural y aplicando, por un lado, el método Physical Habitat Simulation Model (PHABSIM), el que se fundamenta en la caracterización del hábitat a través de curvas que representen el comportamiento de la fauna acuática, asociados a caudales y velocidades en los tramos del cauce del río; de otro lado, se empleó la metodología de Incremento del Caudal (IFIM) desarrollado por Stalnaker en 1,995. Este método considera la descarga de flujo mínimo, con el aporte de los aspectos bióticos del cauce y el caudal. Este 
método considera la descarga de flujo mínimo, con el aporte de los aspectos bióticos del cauce y el caudal. Este método implica desarrollar una evaluación detallada del tramo a ser afectado para el cual se determinará el caudal ecológico.

Para la aplicación del método descrito, se utilizó a la especie íctica característica en la cuenca alta del río Apurimac, la trucha (Oncorhynchus mykiss), que es especie anádroma y mejor adaptada a las características hidráulicas, estructurales $\mathrm{y}$ geomorfológicas de la zona de estudio. Al conocer cómo afecta el caudal a estas características que posee la trucha en sus diversos estadios, especialmente juvenil y adulto que requieren un caudal determinado de agua para remontar río arriba y reproducirse, se puede predecir el caudal óptimo para mantener las poblaciones de las truchas. En razón a ello, entre los métodos más utilizados se encuentra: Instream Flow Incremental Methodology: Desarrollado también por la US Fish and Wildlife Service (Armour \& Taylor, 1991), este integra modelos analíticos hidráulicos junto con el estudio de la calidad del agua, sedimentos, estabilidad de los cauces, temperatura y otras variables que afectan la producción de peces. El método consiste en la construcción de índices que muestran el grado de adaptación de especies objetivos a diferentes valores de velocidad, profundidad y características geomorfológicas específicas.

La hidrometría es la parte de la hidráulica que tiene por objeto medir el volumen de agua que pasa por unidad de tiempo por una sección transversal de un río (WWF, 2010). Son varios los métodos que se pueden emplear para aforar el agua, la mayoría de ellos basado en los parámetros que determinan el caudal de agua y que los podemos resumir en la ecuación siguiente:

$\mathrm{Q}=\mathrm{A} \times \mathrm{v}$

Donde

Q: es el caudal de agua, se expresa en $1 / \mathrm{s} \mathrm{o} \mathrm{m}^{3} / \mathrm{s}$

A: es el área de la sección transversal del flujo de agua, se expresa en $\mathrm{m}^{2}$

v: es la velocidad media del agua, se da en $\mathrm{m} / \mathrm{s}$.

Para la determinación de los caudales se utilizó un Correntómetro de hélices FP111.

\section{Resultados}

La evapotranspiración calculada, utilizando las ecuaciones de Penman-Monteith y Hargreaves para cuatro localidades ubicadas en la pradera andina de Espinar se muestra en la Tabla 1.

Tabla 1: Evapotranspiración de referencia (ETo) por método de Hargreaves y Penman-Monteith; datos promedio.

De la información de la Tabla 1, se colige que para el ámbito de estudio la evapotranspiración de referencia (ETo), difiere entre los meses secos y fríos (abril-setiembre) que en promedio alcanza $2.71 \mathrm{~mm}$; en cambio, en los meses 
lluviosos (octubre-marzo) la ETo llega a valores promedio de $3.46 \mathrm{~mm}$; es decir, 1.3 veces más; ciertamente, la precipitación superior a los $800 \mathrm{~mm} / \mathrm{año} \mathrm{hace}$ que las pasturas tengan la cantidad de agua suficiente para el crecimiento.

\section{Caudales ofertados por los principales ríos en la cuenca alta del río Apurimac}

Tabla 2. Caudales promedio del río Apurimac en su cuenca alta (m³/s). 2009.

De la información de la tabla precedente, se colige que el río Apurimac en su cuenca alta oferta, en promedio, un caudal de $11.42 \mathrm{~m}^{3} / \mathrm{s}$, con máximas de hasta $87.48 \mathrm{~m}^{3}$ y con mínimas inferiores a $2 \mathrm{~m}^{3}$ en temporada de secas; esta información, permite especificar que se hace necesario el afianzamiento hídrico a efecto de utilizar el riego tecnificado para agricultura y cultivo de pasturas y otros usos consuntivos y no consuntivos. De la medición de caudales en época de precipitación efectuada el 2010, para los tributarios del río Apurimac, se tiene:

Tabla 3. Caudales de los principales tributarios del río Apurimac en su cuenca alta.

El río Apurimac en el ámbito de estudio tiene una superficie de escorrentía de más de 5,000 $\mathrm{Km}^{2}$, y con una temporada de lluvias abundante, puede multiplicar su caudal en 15 veces; sin embargo, cabe manifestar que este caudal es excepcional y atípico. El caudal del Apurimac se incrementa considerablemente en el periodo lluvioso.

\section{Estimaciones de la demanda en usos consuntivos y no consuntivos Requerimiento de riego en pasturas y cultivos.}

La cantidad de agua que las plantas transpiran es mucho mayor que la que retienen (la que usan para crecimiento y fotosíntesis). En una parcela, es difícil separar la evaporación y la transpiración, cuando se habla de las necesidades de agua en los cultivos, por lo que la suma de ambos procesos se le ha denominado como evapotranspiración (Allen et al, 2006); por lo tanto, el agua evapotranspirado debe reponerse periódicamente al suelo para no dañar el potencial productivo de la planta por estrés hídrico. Diversas metodologías se han propuesto para su determinación, debiendo considerarse siempre que la evapotranspiración depende, entre otros aspectos, de las condiciones climáticas, tipo y estado de desarrollo del cultivo, así como de la disponibilidad de agua del suelo.

Derivado de estos procesos en 1950, Blaney y Criddle definieron "uso consuntivo o evapotranspiración" como "la suma de los volúmenes de agua usados por el crecimiento vegetativo de una cierta área por conceptos de transpiración y formación de tejidos vegetales y evaporada desde el suelo adyacente, proveniente de la nieve o precipitación interceptada en el área en cualquier tiempo dado, dividido por la superficie del área"; en la siguiente figura se muestra la curva de crecimiento de pastos naturales cuando la humedad del suelo se halla saturada.

Figura 2. Curva de crecimiento de los pastos. 
Como se desprende, el gráfico expresa que existen dos fases de crecimiento rápido, por lo tanto, de alto consumo hídrico; ello implica que el suelo debe estar abastecido de agua suplementaria mediante el riego. Entre las especies más conocidas tenemos a Festuca dolichophylla (chilligua), Festuca weberbaueri; Calamagrostis antoniana; Calamagrostis recta, Stipa ichu (ichu), Stipa obtusa. También se observa el denominado césped de puna representado por especies de los géneros Pycnophyllum, Azorella, Aciachne, Werneria siendo las especies más conocidas: Pycnophyllum molle, Azorella diapensoides (pasto estrella), Calamagrostis vicunarum (crespillo).

De otro lado, la presencia del agua genera la producción de pastos, permitiendo la renovación de las reservas de las plantas para mantener su vigor y permitiendo la máxima productividad en el mediano y largo plazo. Los pastos capturan energía solar mediante sus hojas verdes a través de la fotosíntesis. La energía es convertida a carbohidratos para su crecimiento o ser almacenada para usarse después. En la Fase 1, las plantas tienen menos hojas y realizan menos fotosíntesis, su crecimiento es lento y tienen que utilizar parte de los carbohidratos almacenados. En la Fase 2, las plantas tienen más hojas, su crecimiento es rápido, su fotosíntesis es mayor, debido a la alta solaridad, lo cual les permite almacenar carbohidratos. En la última fase, la fotosíntesis disminuye debido al sombreo de las hojas superiores; además que la energía capturada se utiliza para la floración y formación de semillas. La calidad nutricional del forraje disminuye, a medida que las plantas se desarrollan, tienen más tallos, concentración de fracciones fibrosas y menos concentración de proteína cruda. Además, es necesario señalar que, en los meses secos, si no hay lluvia, la fase última es de decaimiento.

\section{a. Necesidades de riego}

Referidas a la cantidad de agua y al momento de su aplicación, a fin de compensar el déficit de humedad del suelo durante un periodo vegetativo; se determina utilizando la evapotranspiración del cultivo en consideración (ETc) menos el agua aportada por las precipitaciones. Cuando la precipitación efectiva es mayor que las necesidades de riego, la demanda o riego bruto es igual a cero (0). En caso contrario, cuando la precipitación efectiva es menor al uso consuntivo del cultivo, la demanda se define por la diferencia entre la ETc y el agua que se aporta por precipitación.

\section{b. Estimaciones y cálculo}

El uso del agua en la producción agrícola y en el riego de pasturas se establece en función de las necesidades de riego de los diferentes cultivos (Crassi, 1967). Está referido a la cantidad de agua y al momento de su aplicación, a fin de alcanzar un equilibrio entre la cantidad de agua requerida por el cultivo, en compensación por la pérdida por evapotranspiración, y la precipitación efectiva. Entonces, la necesidad de riego representa la diferencia entre el requerimiento de agua del cultivo y la precipitación efectiva, más un componente de agua adicional para el lavado de sales de los suelos y para compensar la falta de uniformidad o eficiencia en la aplicación de los sistemas de riego (Doorenbos, 1976).

Tabla 4. Uso actual de suelos en distritos de la cuenca alta del río Apurimac 
De conformidad a la información proporcionada por la tabla precedente, exceptuando el distrito de Pichigua por estar fuera del ámbito de estudio, la superficie total pasible de riego alcanza una extensión de 271,657 ha (suelos con pastos naturales y cultivos); de esta superficie de pastos naturales y cultivos, es necesario determinar el área efectiva a ser irrigada; esto es, con una pendiente del $25 \%$, que en el ámbito de estudio en territorio de Espinar corresponde al 52.25\% de esa superficie; consecuentemente, el área sujeta a irrigación alcanzaría a una extensión de 141,940.78 ha. Sin embargo, es menester considerar que alrededor del 32\% de esa superficie se halla en el área de influencia directa del río Apurimac; esto es aproximadamente 45,421 ha.

Considerando que la demanda de agua es de 1L/s/ha (Plan MERISS, 2009); entonces un cálculo rápido permite estimar que se requerirían alrededor de $45.4 \mathrm{~m}^{3} / \mathrm{s}$. De otro lado, es necesario tener en cuenta la capacidad de retención de humedad de los suelos en el ámbito de estudio; la planicie de Espinar cuenta con una variada calidad de suelos, unos ricos en materia orgánica en sus primeros estratos, otras zonas presentan suelos arcillosos y areno-gravosos; la capacidad de retención, varía con la textura, estructura y composición química. Para fines de riego, la capacidad de retención de humedad se considera como la diferencia entre la capacidad de campo y punto de marchitamiento (Garay, 2009). Multiplicando la profundidad radicular por el almacenamiento de los suelos se obtiene la cantidad total del agua aprovechable para las plantas.

Figura 3. La extensa pradera andina en Espinar puede ser irrigada con tecnología adecuada y hacerla productiva.

\section{Demanda hídrica en el sector pecuario}

Según la ASCE (1973), la estimación de la demanda hídrica pecuaria se define en términos del consumo de agua del hato ( $\mathrm{L} /$ cabeza/día) y se realiza mediante la adopción de módulos de consumo aplicados diferencialmente en la cadena de producción. Se agrega así el volumen de agua utilizada en las fases de crecimiento, terminación y de sacrificio, y en los lugares de manejo y beneficio de la población de bovinos, ovinos, camélidos sudamericanos, porcinos y aves.

El concepto de población cubre la totalidad de los inventarios de población en camélidos sudamericanos, ovinos, bovinos, porcinos e incluso aves, con las siguientes particularidades:

- En el caso del inventario ganadero (alpacuno, vacuno y, ovino), desagregado por grupos etarios y por finalidad o propósito productivo;

- $\quad$ En el caso de la población de porcinos y aves, se consideran tanto el inventario de animales de traspatio o en unidades agropecuarias de los hogares;

- El dato de población asociada al sacrificio incluye el sacrificio formal y el sacrificio no registrado.

Tabla 5. Carga Productiva en distritos de la cuenca alta del Apurimac. Población animal. 
La cuenca alta del río Apurimac, bajo la información oficial, cuenta con 354,200 unidades, cuyo manejo requiere de pastos frescos y ensilados y de agua para la alimentación y sanidad respectiva.

Figura 4. Considerando la aptitud de los suelos para la soportabilidad del ganado, existe ya una distribución en las crianzas. El ganado vacuno se halla en la planicie baja, los ovinos en la zona intermedia y los camélidos sudamericanos en las partes más altas; todos con una biodiversidad interesante de pasturas palatables.

Las observaciones de campo y considerando la aptitud de los suelos para la soportabilidad del ganado, existe ya una distribución en las crianzas. El ganado vacuno se halla en la planicie baja, los ovinos en la zona intermedia y los camélidos sudamericanos en las partes más altas; todos con una biodiversidad interesante de pasturas palatables.

De conformidad a las estimaciones efectuadas por el MINAGRI (2004), la demanda por ejemplar es de $10 \mathrm{~L} /$ día/unidad; la demanda hídrica sólo de camélidos sudamericanos referidos en la tabla 8 , alcanzarían a $0.026 \mathrm{~m}^{3} / \mathrm{s}$ para los camélidos en los distritos de la cuenca alta del río Apurimac y en el ámbito de estudio. A ello se debe de agregar el requerimiento de vacunos, ovinos, equinos, porcinos y animales menores, que según la información oficial es de 306,365; por lo tanto, la demanda total y con el mismo requerimiento alcanza a $0.035 \mathrm{~m}^{3} / \mathrm{s}$.

\section{Demanda hídrica en sistemas de producción acuícola}

La piscicultura es definida como la actividad dedicada al cultivo de peces mediante el manejo e implementación de buenas prácticas de alimentación, reproducción y sanidad de las especies. En Espinar, está orientada hacia la producción de truchas en estanques y en sistemas de tierra.

\section{a. Unidades de observación.}

Una granja piscícola dotada con estanques, confinados con sistemas de recirculación de agua y sistemas de producción controlados sobre cuerpos de agua corriente, en donde se desarrolla dicha actividad, requiere agua; conforme a la experiencia de la truchicultura en la zona andina (FONDEPES, 2014), se puede colegir que se requieren mínimamente estanques de $200 \mathrm{~m}^{2}$ y $0.60 \mathrm{~m}$ de profundidad, esto es, un mínimo de $120 \mathrm{~m}^{3}$ de volumen.

\section{b. Cálculo de la demanda en piscicultura}

La demanda de agua en la producción acuícola hace alusión al volumen de agua $\left(\mathrm{m}^{3}\right)$ utilizada en instalaciones o infraestructura en tierra (estanques), confinadas con sistemas de recirculación de agua para la siembra y producción de especies piscícolas.

Para el cálculo de la demanda de agua, se utiliza la variable de producción en toneladas/año de peces de la especie Oncorhynchus mykiss (trucha). A este valor de producción se le asocia un valor específico correspondiente al rendimiento anual, a densidades finales (biomasa final), que se expresa en $\mathrm{kg} / \mathrm{m}^{3}$ (Fitzsimmons, 2000), aplicable diferencialmente a la producción confinada con sistemas de recirculación 
en tierra. Al dato de demanda, obtenido mediante esta operación (producción y biomasa final), se incrementa un $30 \%$ con el objeto de considerar el recambio de agua en las fases iniciales de la cadena de producción, conforme a las prácticas culturales del cultivo en instalaciones $o$ infraestructura en tierra.

Para el cultivo de la trucha, se utilizan estanques de concreto o tierra rectangular de $200 \mathrm{~m}^{2}$ y $50 \mathrm{~m}^{2}$, con una profundidad promedio de $0.60 \mathrm{~m}$. Como fuente de agua podrá utilizarse agua del río Apurimac y tributarios. Se contempla la construcción de un desarenador inmediatamente después de la toma de agua, debido a que la trucha es sensible a los sólidos suspendidos en el agua. La densidad de siembra será de 34 truchas por $\mathrm{m}^{2}$ en la etapa final en los estanques de $200 \mathrm{~m}^{2}$. En el caso de la producción de trucha, la densidad final de siembra puede variar entre 100 y 400 peces $/ \mathrm{m}^{3}$, lo cual equivale a capacidades de carga o rendimientos a densidades finales de 30 a $130 \mathrm{~kg} / \mathrm{m}^{3}$.

Considerando la calidad óptima de las aguas en Espinar, temperaturas adecuadas, alta concentración de oxígeno disuelto, aguas límpidas con bajo contenido de sólidos en suspensión, la truchicultura resultaría siendo una actividad económica de interés para las poblaciones locales. La información parcial obtenida del sector Producción señala que en el 2010 se comercializaron $15,000 \mathrm{~kg}$. todos ellos provenientes de las aguas del río Apurimac y tributarios (PRODUCE, 2015; MINAM, s/f).

Para el cálculo de la demanda potencial, se puede inferir que con las aguas de los ríos de Espinar se puede efectuar crianzas de hasta 200 truchas $/ \mathrm{m}^{3}$; si para la comercialización se recomienda un peso de $0.300 \mathrm{~kg}$; entonces se tendría una capacidad de carga final de $60 \mathrm{~kg} / \mathrm{m}^{3}$; consecuentemente, en un estanque de $200 \mathrm{~m}^{2}$ y $0.60 \mathrm{~m}$ de profundidad con un volumen de manejo de $120 \mathrm{~m}^{3}$, se tendría una producción de 7,200 kg. Esto quiere decir que cada trucha en la etapa de comercialización requiere 5 litros de agua. Al volumen calculado para cada estanque $\left(120 \mathrm{~m}^{3}\right)$ se debe de añadir un $30 \%$ que constituye el recambio de agua constante, esto es, $36 \mathrm{~m}^{3}$. Si a futuro se instalaran 500 estanques con ese volumen, entonces se requeriría $78,000 \mathrm{~m}^{3}$ de agua que albergarían 12 millones de truchas; como quiera que cada trucha requiera $0.005 \mathrm{~m}^{3} /$ día de agua; entonces la demanda hídrica para la truchicultura en Espinar sería de $0.69 \mathrm{~m}^{3} / \mathrm{s}$.

\section{Caudal ecológico}

Aplicable a la demanda de los ecosistemas presentes en la cuenca tanto del Apurimac como en la de sus tributarios. Podemos definirla como el volumen de agua necesario en términos de calidad, cantidad, duración y estacionalidad para el sostenimiento de los ecosistemas acuáticos y para el desarrollo de las actividades socioeconómicas de los usuarios aguas abajo de la fuente de la cual dependen tales ecosistemas (Stalnaker et al, 1995; WWF, 2010).

Figuras 5. El caudal ecológico calculado en el 2010, fue de $2.6 \mathrm{~m}^{3} / \mathrm{s}$; UNOPS, determinó $2.4 \mathrm{~m} 3 / \mathrm{s}$. Este caudal debe discurrir a lo largo del río. 
El caudal ecológico calculado en el 2010, fue de $2.6 \mathrm{~m} 3 / \mathrm{s}$; UNOPS, determinó $2.4 \mathrm{~m}^{3} / \mathrm{s}$. Este caudal debe discurrir a lo largo del río. El caudal ecológico no debe ser considerado para el cálculo de las demandas consuntivas y debe ser considerado desde sus nacientes y a lo largo del rio. Por lo tanto, el caudal ecológico que debe discurrir a lo largo del río y no debe ser utilizado para ningún uso, es de $2.6 \mathrm{~m} / \mathrm{s}$.

\section{Demanda para consumo humano.}

En el ámbito de análisis se hallan ubicados los distritos de Espinar, Coporaque y Suykutambo, que totalizan una población, para el 2020, de 71,981 habitantes; cabe resaltar que Yauri, la capital de Espinar es urbana, por lo tanto, la demanda de agua se estima con un requerimiento de $100 \mathrm{~L} / \mathrm{hab} /$ día; en cambio los distritos de Coporaque y Suykutambo son rurales, por lo que su demanda se estima con $70 \mathrm{~L} / \mathrm{hab} /$ día.

Por lo arriba anotado la demanda de agua de consumo para el distrito de Espinar sería de $0.05 \mathrm{~m}^{3} / \mathrm{s}$ y para la población proyectada de los distritos de Coporaque y Suykutambo sería de $0.023 \mathrm{~m}^{3} / \mathrm{s}$; consecuentemente la demanda total proyectada para el año 2020 sería de $0.073 \mathrm{~m}^{3} / \mathrm{s}$.

\section{Demanda para recreación y turismo}

Esta demanda es la misma que el caudal ecológico o ambiental. El turismo y recreación en la cuenca alta del río Apurimac, tiene un incremento constante.

\section{Estimaciones de la demanda total}

Tabla 6. Comparativo de las demandas estimadas, según actividad.

Por lo tanto, efectuando los cálculos, se estima que la demanda hídrica en la cuenca alta del río Apurimac para las actividades de riego, pecuaria, consumo humano, truchicultura y el caudal ecológico es de $48.8 \mathrm{~m}^{3} / \mathrm{s}$ requeridos para irrigar 45,421 ha, satisfacer la demanda para consumo humano, actividades pecuarias, piscicultura y mantener el caudal ecológico.

\section{Discusión}

De conformidad a la propuesta de Crassi, 1967, el uso del agua en la producción agrícola y en el riego de pasturas se establece en función de las necesidades de riego de los diferentes cultivos; en el presente estudio, se consideró, además, la evapotranspiración en razón a la alta solaridad existente en el ámbito de estudio.

En el cálculo de la demanda de agua en actividades acuícolas, de acuerdo con Fitzsimmons, K. 2000, se debe de incrementar un 30\% con el objeto de considerar el recambio de agua en las fases iniciales de la cadena de producción, conforme a las prácticas culturales del cultivo en instalaciones o infraestructura en tierra; en el caso de la determinación del requerimiento de agua para truchicultura en Espinar, sólo se agregó ese porcentaje para las piscigranjas y no para la actividad piscícola en los ríos.

Para el ámbito de estudio, efectuaron estimaciones del requerimiento hídrico en 
diversas actividades instituciones como el MINAGRI, Plan MERISS y GoRe Cusco,empero no incluyeron las diversas demandas que el presente estudio ha considerado; en algunos casos, no incluyeron el caudal ecológico, la piscicultura, las actividades pecuarias, el requerimiento humano o el riego de pasturas; en cambio nuestra propuesta incluye todas esas variables de consumo; por lo tanto, efectuando los cálculos, se estima que la demanda hídrica en la cuenca alta del río Apurimac para las actividades de riego, pecuaria, consumo humano, truchicultura y el caudal ecológico es de $48.8 \mathrm{~m}^{3} / \mathrm{s}$ requeridos para irrigar 45,421 ha, satisfacer la demanda para consumo humano, actividades pecuarias, piscicultura y mantener el caudal ecológico. Nuestro estudio señala que se hace necesario el afianzamiento hídrico en la cuenca alta del río Apurimac a efecto de utilizar el riego tecnificado para agricultura y cultivo de pasturas y otros usos consuntivos y no consuntivos.

Farfán et al (2012), señalan que los pastos cultivados son de alta producción, por consiguiente, necesitan riegos periódicos que debe empezar en el mes de abril, una vez a la semana, dejando correr $4.6 \mathrm{~L} / \mathrm{s} / \mathrm{ha}$ de agua durante 8 horas; este cálculo es efectuado para cultivos bajo condiciones controladas y en condiciones de ensayo; nuestros estudios, en cambio estiman 1L/s/ha, bajo condiciones de riego tecnificado.

Tapia (1972) realizó una clasificación de los pastizales propiamente dichos, en la cual se ha considerado las condiciones ecológicas, composición botánica y la utilización o modificación que hubiese efectuado el hombre; esta clasificación solamente se refiere a los pastizales del Altiplano Peruano cuya estratigarfía y geología son diferentes a la zona de estudio; no obstante, las especies señaladas por Tapia y por nuestro estudio son coincidentes en las especies: Festuca dolichophylla (chilligua); Calamagrostis vicunarum (crespillo); Distichia muscoides, Stipa ichu (ichu); Festuca orthophylla (iro ichu) y, Stipa obtusa.

Zea (2015) concluye que utilizando el método de Penman Monteith determina la ETo para pastizales secos en Puno y determina una media estimada de $3.69 \mathrm{~mm} / \mathrm{mes}$; nuestro estudio calcula una ETo de $3.29 \mathrm{~mm} / \mathrm{mes}$; probablemente esta diferencia se debe a la geología local y a las características del suelo.

Collaguayo (2014) concluye que el requerimiento de agua en el cultivo de pastos con manejo convencional en zonas superiores de 3,000 m.s.n.m. es de $0.35 \mathrm{~L} / \mathrm{s} / \mathrm{ha}$; el presente trabajo, difiere de esta conclusión, pues el requerimiento de agua para pasturas naturales, así como para cultivos es de $1 \mathrm{~L} / \mathrm{s} / \mathrm{ha}$.

\section{Conclusiones}

Es necesario el afianzamiento hídrico en la cuenca alta del río Apurimac a efecto de utilizar el riego tecnificado para agricultura y cultivo de pasturas y otros usos consuntivos y no consuntivos, debido a que existe una fluctuación sustancial en el caudal de los ríos, en las dos estaciones marcadas del año; en temporada lluviosa supera $\operatorname{los} 87 \mathrm{~m}^{3} / \mathrm{s}$ y en época de secas es inferior a $2 \mathrm{~m}^{3} / \mathrm{s}$. 
La pradera andina en Espinar y en el área de influencia directa del río Apurimac en su cuenca alta formada sustancialmente por pasturas de alta palatabilidad para camélidos sudamericanos, ovinos y vacunos poseen un alto consumo hídrico por la evapotranspiración alta; ello implica que el suelo debe estar abastecido de agua suplementaria mediante el riego; se ha calculado que existe un área sujeta a irrigación en una extensión de 141,940.78 ha, con una pendiente del $25 \%$.

El caudal ecológico que debe discurrir a lo largo del río y no debe ser utilizado para ningún uso, es de $2.6 \mathrm{~m}^{3} / \mathrm{s}$. Este caudal debe ser considerado como intangible por las autoridades que administran este recurso.

La demanda hídrica en la cuenca alta del río Apurimac para las actividades de riego, pecuaria, consumo humano, truchicultura y el caudal ecológico es de $48.8 \mathrm{~m}^{3} / \mathrm{s}$ requeridos para irrigar $45,421 \mathrm{ha}$, satisfacer la demanda para consumo humano, actividades pecuarias, piscicultura y mantener el caudal ecológico.

La altitud influye notablemente en el tiempo de duración del estado fenológico de los pastos, especialmente en la etapa de secas y heladas, debido que cada zona cuenta con características ambientales propias en especial la temperatura y la velocidad de viento.

Debido a las condiciones ambientales de la pradera en Espinar, la producción de pastos sigue el patrón de la precipitación pluvial, es decir, durante los meses lluviosos (octubre-marzo) existe abundancia, mientras que en los meses de estío (abril-octubre) existe escasez, que podría ser disminuido mediante programas de riego.

\section{Agradecimientos.}

Expreso mi público reconocimiento al Ing. Carlos Loayza Schiafino, docente de la Facultad de Ing. Civil de la UNSAAC por su apoyo en los trabajos de campo y en el aforo de los ríos en estudio; igualmente a los funcionarios de las estaciones meteorológicas de Angostura y Yauri por facilitar la información meteorológica.

\section{Declaración de conflicto de intereses.}

El autor declara no tener conflictos de intereses financieros ni personales que puedan influir inapropiadamente en el desarrollo de este artículo. 


\section{Referencias}

Allen R.G., L.S. Pereira, D. Raes y M. Smith. (2006). Evapotranspiración del cultivo. Guías para la determinación de los requerimientos de agua de los cultivos. Estudio FAO Riego y Drenaje $N^{\circ} 56$, Organización de las Naciones Unidas para la Agricultura y Alimentación, Roma, 298 pp.

Armour, Carl L. \& Taylor, Jonathan G. (1991). Evaluation of the Instream Flow Incremental Methodology by U.S. Fish and Wildlife Service Field Users, Fisheries, 16:5, 36-43, DOI: 10.1577/1548-8446(1991)016<0036:EOTIFI $>$ 2.0.CO;2

Autoridad Nacional del Agua-ANA. (2016). Metodología para Determinar Caudales Ecológicos. Autoridad Nacional del Agua. Lima, Perú.

Autoridad Nacional del Agua-ANA. (2019). Resolución Jefatural No 267-2019-ANA. Lineamientos generales para determinar caudales ecológicos. Lima.

Aguilera. C. M. y Martínez E. R. (1996). Relaciones Agua Suelo Planta Atmosfera. Departamento de Irrigación. Universidad Autónoma Chapingo, México.

Bernex, N.; Yakabi, K; Zuñiga, A; Asto, L. y Verano, C. (s/f). Aprovechamiento del agua. Capítulo 3. Disponible en: http://ciga.pucp.edu.pe/ wp-content/uploads/2017/09/3.-CAPITULO-3.pdf.

Blaney H. y Criddle W. (1950). Determining water requirements in irrigated areas from climatological and irrigation data. USDA Soil Conservation Service. Technical Paper 96 Washington.

Collaguazo Pinango, G.E. (2014). Necesidades hídricas de pasturas con manejo convencional en la zona de influencia del canal de riego Cayambe-Pedro Moncayo. Tesis, Universidad Politécnica Salesiana, sede Quito. Quito.

Crassi, C. J., (1967). Estimación de los Usos Consuntivos de agua y requerimientos de riego con fines de formulación y diseño de proyectos. Material de enseñanza $\mathrm{N}^{\mathrm{o}}$ 53. SIDITA. Mérida, Venezuela.

Doorenbos J. y Pruitt W.O. (1976). Las necesidades hídricas de los cultivos. Estudio FAO. Riego y Drenaje No 24, FAO, Roma.

Doorenbos, J. y W.O. Pruitt W.O. (1982). Clima y Agricultura. Comité Regional de Recursos Hidráulicos. Gobiernos de Costa Rica, El Salvador, Guatemala, Honduras, Nicaragua y Panamá. Publicación No 145, Tegucigalpa.

FAO. (1990). Cálculo de ET0: Método de Penman-Monteith. Expert consultation on revision of FAO methodologies for crop water requirements. Roma. 
FAO. (2006). Evapotranspiración del cultivo. Guías para la determinación de los requerimientos de agua de los cultivos. Estudio FAO Riego y Drenaje No 56. http://ftp.fao.org/docrep/fao/009/x0490s/.

FAO. (2011). Oficina Regional de la para América Latina y el Caribe. Taller de expertos sobre métodos de evaluación de recursos hídricos y usos del agua en América Latina. AQUASTAT es el sistema de información global sobre el uso del agua en la agricultura y el medio rural, desarrollado por la División de Tierras y Aguas de la FAO. Santiago - Chile.

Farfán, Ramiro y Farfán Eyleen. (2012). Producción de Pasturas Cultivadas y Manejo de Pastos Naturales Altoandinos. Moquegua: INIA-Gobierno Regional de Moquegua, 2012. 249 pp

Fitzsimmons, K. (2000). Tilapia: the most important aquaculture species of the 21st century. Environmental Research Lab. University of Arizona. Tucson.

Flórez Martínez, Arturo. (2005). Manual de pastos y forrajes altoandinos. ITDG, OIKOS. Lima.

Fondo Nacional de Desarrollo Pesquero-FONDEPES. (2014). Manual de Crianza de Trucha en Ambientes Convencionales. Recuperado de https://www.fondepes .gob.pe/src/manuales/MANUAL_TRUCHA.pdf

Fuentes, J. L. (2003). Técnicas de Riego. Madrid, España: Grupo Mundi-Prensa.

Garay Canales, Oscar Baldomero. (2009). Manual de uso consuntivo del agua para los principales cultivos de los Andes Centrales Peruanos. INCAGRO, Estación Experimental INIA Santa Ana. El Tambo - Huancayo - Perú.

García, E. (2009). Manual Práctico de Pequeñas Irrigaciones. Editado en junio de 2009, según Fondo Perú - Alemania, pp. 46 - 47.

Hargreaves, G. \& Samani, Z. (1985). Reference crop evapotranspiration from temperature. Appl. Eng. in Agr. P. 96-99.

Jensen, Marvin E. (1973). Consumptive Use of Water and Irrigation Water Requirements. A Report by The Technical Committee on Irrigation Water Requirements of the Irrigation and Drainage Div. of American Society of Civil Engineers. New York.

Martínez E.R. (1991). Riego Localizado, Diseño y Evaluación. Comité editorial del departamento de Irrigación. Universidad Autónoma Chapingo, México.

Ministerio de agricultura. Dirección de Crianzas. (2004). Manual de manejo de pastos cultivados para zonas alto andinas. Lima. 
Ministerio de agricultura. D.S. 017·2009·AG. (2009). Reglamento de Clasificación de Tierras por su Capacidad de Uso Mayor. Lima.

Ministerio de Agricultura-Autoridad Nacional del Agua. (2010). Reglamento de la Ley de Recursos Hídricos. Ley 29338. Lima.

Ministerio del Ambiente. (s/f). Línea de Base de la Trucha: Distribución, Aspectos Socioeconómicos y Flujo de Genes en Seis Regiones. Dirección General de Diversidad Biológica. Lima.

Ortiz C. Randon y Chile A. Maritza. (2018). Métodos de cálculo para estimar la evapotranspiración de referencia para el Valle de Tumbaco-Ecuador. Revista digital Siembra-Universidad Central del Ecuador, Ecuador. DOI: https://doi.org/10.29166/siembra.v7i1.1450

Milla, C. (2015). Estudio Hidrológico para la Acreditación de la Disponibilidad Hídrica Superficial de las quebradas Caninaco, San Luis y Laguna Huachucocha. Octubre de 2015, pp. 97 - 98.

Monteith, J.L., (1965). Evaporation and Environment. 19th Symposia of the Society for Experimental Biology, University Press, Cambridge, 19:205-234.

Monteith, J.L. (1985). Evaporation from land surfaces: progress in analysis and prediction since 1948. pp. 4-12 in Advances in Evapotranspiration, Proceedings of the ASAE Conference on Evapotranspiration, Chicago, Ill. ASAE, St. Joseph, Michigan.

Penman, H.L. (1963). Vegetation and hydrology. Tech. Comm. No. 53, Commonwealth Bureau of Soils, Harpenden, Reino Unido. 125 pp.

Piñas, Jesús Antonio. (2009). Manual Técnico: Técnicas y Uso Racional del Agua de Riego en la Sierra. Universidad Nacional de Huancavelica-Facultad de Ciencias Agrarias. Escuela Académico Profesional de Huancavelica.

PRODUCE. (2015). Especies Cultivadas en el Perú. Fichas técnicas. 20 pág. Disponible en: http://www2.produce.gob.pe/RepositorioAPS/3/jer/ ACUISUBMENU4/boletines/FICHAS\%20PRINCIPALES\%20ESPECIES.pdf

Proyecto Especial Plan MERISS. (2009). Desarrollo tecnológico y manejo del agua. Gobierno Regional del Cusco. Cusco.

SENAMHI. (2010). Boletín Climático Nacional. 2010. Disponible en: https://www. senamhi.gob.pe/load/file/01401SENA-77.pdf

Stalnaker, C; Lamb, B; Henriksen, J; Bovee, K. y Bartlow, J. (1995). The Instream Flow Incremental Methodology. A Primer for IFIM. US Department of Interior National Biological Service, Washington D.C. 
Tapia M. (1972). Pastos Naturales del Altiplano del Perú y Bolivia. Publ. 으 34. IICA-Lima-Perú.

Thornthwaite, C. (1948). An approach toward a Rational Classification of Climate. American Geographical Society, 38(1), 55-94.

Walter, I. A.; Allen, R. G.; Elliot, R.; Itenfisu, D.; Brown, P.; Jensen, M. E.; Mecham, B.; Howell, T. A.; Snyder, R.; Eching, S.; Spofford, T.; Hattendorf, M.; Martin, D.; Cuenca, R. H. and Wright, J. L. (2005). The ASCE standardized reference evapotranspiration equation. ASCE and EWRI. 70 p.

WWF. (2010). Serie Seguridad Hídrica de WWF-2. Cómo conservar los ríos vivos. Guía sobre los caudales ecológicos. wwf.org.uk/freshwater. WWF-México.

Zea Mamani, Richar. (2015). Determinación experimental de las necesidades hídricas del bofedal en puna seca y húmeda en el departamento de Puno. Tesis. Universidad Nacional del Altiplano. Puno. 
Tabla 1: Evapotranspiración de referencia (ETo) por método de Hargreaves y Penman-Monteith; datos promedio.

\begin{tabular}{llllllllllllll}
\hline Lugar & \multicolumn{1}{c}{ ETo mensual (mm/día) } & \multicolumn{1}{c}{ Métodos Hargreaves y Penman-Monteith - 2010 } & Media \\
\hline & Ene & feb & Mar & Abr & May & Jun & Jul & Ag & Set & Oct & Nov & Dic & \\
Coporaque & 3.47 & 3.59 & 3.23 & 2.95 & 2.30 & 2.08 & 2.20 & 2.68 & 3.19 & 3.81 & 4.35 & 3.84 & 3.14 \\
Yauri & 3.57 & 3.58 & 3.21 & 2.90 & 2.37 & 2.23 & 2.12 & 2.74 & 3.08 & 3.80 & 3.88 & 3.91 & 3.12 \\
Sañu & 2.91 & 3.37 & 3.14 & 3.28 & 2.96 & 2.75 & 2.82 & 3.35 & 3.88 & 3.94 & 4.29 & 3.57 & 3.36 \\
Urinsaya & 2.70 & 2.88 & 2.61 & 2.54 & 2.40 & 2.29 & 2.34 & 2.77 & 2.96 & 2.98 & 3.39 & 2.98 & 2.74 \\
\hline Media & $\mathbf{3 . 1 6}$ & $\mathbf{3 . 3 5}$ & $\mathbf{3 . 0 5}$ & $\mathbf{2 . 9 2}$ & $\mathbf{2 . 5 1}$ & $\mathbf{2 . 3 4}$ & $\mathbf{2 . 3 7}$ & $\mathbf{2 . 8 9}$ & $\mathbf{3 . 2 8}$ & $\mathbf{3 . 6 3}$ & $\mathbf{3 . 9 8}$ & $\mathbf{3 . 5 8}$ & $\mathbf{3 . 0 9}$
\end{tabular}

Tabla 2. Caudales promedio del río Apurimac en su cuenca alta ( $\left.\mathrm{m}^{3} / \mathrm{s}\right) .2009$.

\begin{tabular}{llllllllllllll}
\hline $\begin{array}{l}\text { Caudal } \\
\left(\mathrm{m}^{3} / \mathrm{s}\right)\end{array}$ & Ene & Feb & Mar & Abr & May & Jun & Jul & Ago & Set & Oct & Nov & Dic & $\begin{array}{l}\text { Prom. } \\
\text { Anual }\end{array}$ \\
\hline Media & 20.37 & 33.09 & 34.28 & 12.63 & 5.87 & 4.66 & 4.02 & 3.74 & 3.64 & 3.58 & 4.40 & 6.72 & 11.42 \\
Máx & 64.79 & 76.65 & 87.48 & 27.27 & 11.98 & 7.16 & 6.41 & 6.36 & 6.69 & 6.99 & 9.97 & 25.75 & 22.49 \\
Mín & 3.97 & 4.45 & 4.81 & 3.85 & 2.36 & 1.66 & 1.70 & 1.64 & 1.54 & 1.90 & 1.40 & 1.77 & 2.73 \\
\hline
\end{tabular}

Fuente. E. Gil-C. Loayza, et al. 2010.

Tabla 3. Caudales de los principales tributarios del río Apurimac en su cuenca alta.

\begin{tabular}{|c|c|c|c|c|c|}
\hline Río & $\begin{array}{l}\text { Altitud } \\
\text { (msnm) }\end{array}$ & $\begin{array}{l}\text { Coordenadas } \\
\text { UTM }\end{array}$ & $\begin{array}{l}\text { Área } \\
\left(m^{2}\right)\end{array}$ & $\begin{array}{l}\text { Velocidad } \\
(\mathrm{m} / \mathrm{s})\end{array}$ & $\begin{array}{l}\text { Caudal } \\
\left(\mathrm{m}^{3} / \mathrm{s}\right)\end{array}$ \\
\hline $\begin{array}{l}\text { Suycutambo } \\
\text { (Cuyomani) }\end{array}$ & 3,993 & $\begin{array}{l}\text { 19L0219104 } \\
0342639\end{array}$ & 22.5760 & 0.5482 & 12.3755 \\
\hline $\begin{array}{l}\text { Cerritambo } \\
\text { (Tambomayu) }\end{array}$ & 4,005 & $\begin{array}{l}\text { 19L0219340 } \\
0342465\end{array}$ & 6.0552 & 1.3515 & 2.1282 \\
\hline $\begin{array}{l}\text { Sañu } \\
\text { (puente Sañu) }\end{array}$ & 3,960 & $\begin{array}{l}\text { 19L0225697 } \\
0350472\end{array}$ & 26.2500 & 0.8865 & 23.2711 \\
\hline $\begin{array}{l}\text { Q'ero } \\
\text { (puente Q'ero) }\end{array}$ & 3,924 & $\begin{array}{l}\text { 19L0225574 } \\
0366736\end{array}$ & 71.4240 & 1.3298 & 94.9782 \\
\hline $\begin{array}{l}\text { Huañamayu } \\
\text { (Puente Huañamayu) }\end{array}$ & 3,979 & $\begin{array}{l}\text { 19L0210363 } \\
0369540\end{array}$ & 11.7460 & 1.4116 & 26.4628 \\
\hline $\begin{array}{l}\text { Cangalle } \\
\text { (Puente Cangalle) }\end{array}$ & 3,931 & $\begin{array}{l}\text { 19L0222614 } \\
0367476\end{array}$ & 44.1600 & 1.2896 & 56.9646 \\
\hline
\end{tabular}

Fuente. E. Gil-C. Loayza, et al. 2010 
Tabla 4 Uso actual de suelos en distritos de la cuenca alta del río Apurimac

\begin{tabular}{lllllll}
\hline Tipos de uso & \multicolumn{2}{l}{ Superficie } & \multicolumn{4}{c}{ Distritos } \\
& ha & \% & Espinar & Coporaque & Pichigua & Suykutambo \\
\hline Pastos naturales & 260,651 & 49.08 & 64,257 & 123,874 & 23,248 & 49,272 \\
& & & & & & \\
Cultivos & 38,915 & 7.33 & 6,996 & 20,619 & 4,661 & 6,639 \\
Otros usos & 25,518 & 4.80 & 3,525 & 11,953 & 733 & 9,307 \\
\hline Total & $\mathbf{3 2 5 , 0 8 4}$ & $\mathbf{6 1 . 2 1}$ & $\mathbf{7 4 , 7 7 8}$ & $\mathbf{1 5 6 , 4 4 6}$ & $\mathbf{2 8 , 6 4 2}$ & $\mathbf{6 5 , 2 1 8}$
\end{tabular}

Superficie total provincial: $5,311.09 \mathrm{Km}^{2}$

Fuente. Elaborado en base a la información de MINAGRI, 2004.

Tabla 5. Carga Productiva en distritos de la cuenca alta del Apurimac. Población animal.

\begin{tabular}{lcclccc}
\hline Distritos & Vacunos & Ovinos & Alpacas & Llamas & Equinos & Total \\
\hline Espinar & 13,981 & 1,398 & 64,638 & 5,932 & 4,633 & \\
Pichigua & 6,643 & 664 & 34,261 & 1,602 & 4,665 & \\
Suykutambo & 1,987 & 199 & 18,635 & 15,718 & 7,496 & \\
Coporaque & 18,120 & 1,812 & 95,044 & 23,180 & 33,592 & \\
& & & & & & \\
\hline Total & 40,731 & 4,073 & 212,578 & 46,432 & 50,386 & 354,200
\end{tabular}

Fuente. Elaborado en base a MINAGRI. 2004

Tabla 6. Comparativo de las demandas estimadas, según actividad.

\begin{tabular}{|c|c|c|c|c|}
\hline Actividad & MINAGRI & PLAN MERISS & GORE Cusco & Equipo trabajo \\
\hline Agricultura (1) & $40.98 \mathrm{~m}^{3} / \mathrm{s}(2)$ & $12 \mathrm{~m}^{3} / \mathrm{s}(3)$ & $6.7 \mathrm{~m}^{3} / \mathrm{s}(4)$ & $45.4 \mathrm{~m}^{3} / \mathrm{s}(5)$ \\
\hline Consumo humano & $0.211 \mathrm{~m}^{3} / \mathrm{s}(2)$ & $\mathrm{s} / \mathrm{i}$ & $0.1 \mathrm{~m}^{3} / \mathrm{s}$ & $\begin{array}{l}0.05 \mathrm{~m}^{3} / \mathrm{s}(6) \\
0.023 \mathrm{~m}^{3} / \mathrm{s}(7)\end{array}$ \\
\hline Pecuaria & $0.01 \mathrm{~m}^{3} / \mathrm{s}(2)$ & $\mathrm{s} / \mathrm{i}$ & $\mathrm{s} / \mathrm{i}$ & $0.035 \mathrm{~m}^{3} / \mathrm{s}$ \\
\hline Piscicultura & $\mathrm{s} / \mathrm{i}$ & $\mathrm{s} / \mathrm{i}$ & $\mathrm{s} / \mathrm{i}(8)$ & $0.69 \mathrm{~m}^{3} / \mathrm{s}$ \\
\hline Caudal ecológico & $\mathrm{s} / \mathrm{i}$ & $2.4 \mathrm{~m}^{3} / \mathrm{s}$ & $2.4 \mathrm{~m}^{3} / \mathrm{s}$ & $2.6 \mathrm{~m}^{3} / \mathrm{s}$ \\
\hline Total & $41.201 \mathrm{~m}^{3} / \mathrm{s}$ & $14.4 \mathrm{~m}^{3} / \mathrm{s}$ & $9.2 \mathrm{~m}^{3} / \mathrm{s}(9)$ & $48.8 \mathrm{~m}^{3} / \mathrm{s}$ \\
\hline
\end{tabular}

Fuente. Elaboración propia.

(1) Incluye irrigación de cultivos y pasturas.

(2) Proyectado al año 2058

(3) Para irrigar 12,023.6 ha

(4) Para irrigar 20,000 ha y con déficit de $1.6 \mathrm{~m}^{3} / \mathrm{s}$

(5) Para irrigar 45,421 ha en el ámbito de estudio.

(6) Calculada para Espinar con una demanda de $100 \mathrm{~L} / \mathrm{hab} /$ día por ser urbano.

(7) Calculada para Coporaque y Suykutambo con una demanda de 70 L/hab/día 
(8) Sin información

(9) A esta cifra se debe de añadir el déficit de $1.6 \mathrm{~m}^{3} / \mathrm{s}$, por lo que la demanda ascendería a $10.8 \mathrm{~m} 3 / \mathrm{s}$.

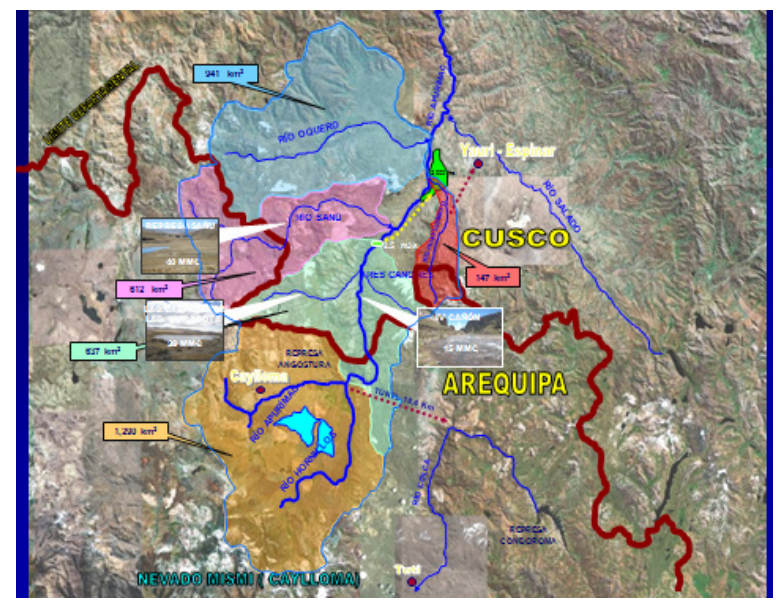

Figura 1. Ámbito de estudio para las determinaciones de demanda hídrica.

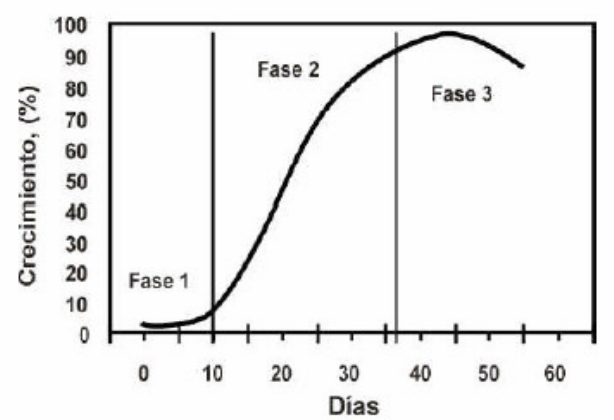

Figura 2. Curva de crecimiento de los pastos.

Fuente. Adaptado de Blaney \& Criddle. 1950.
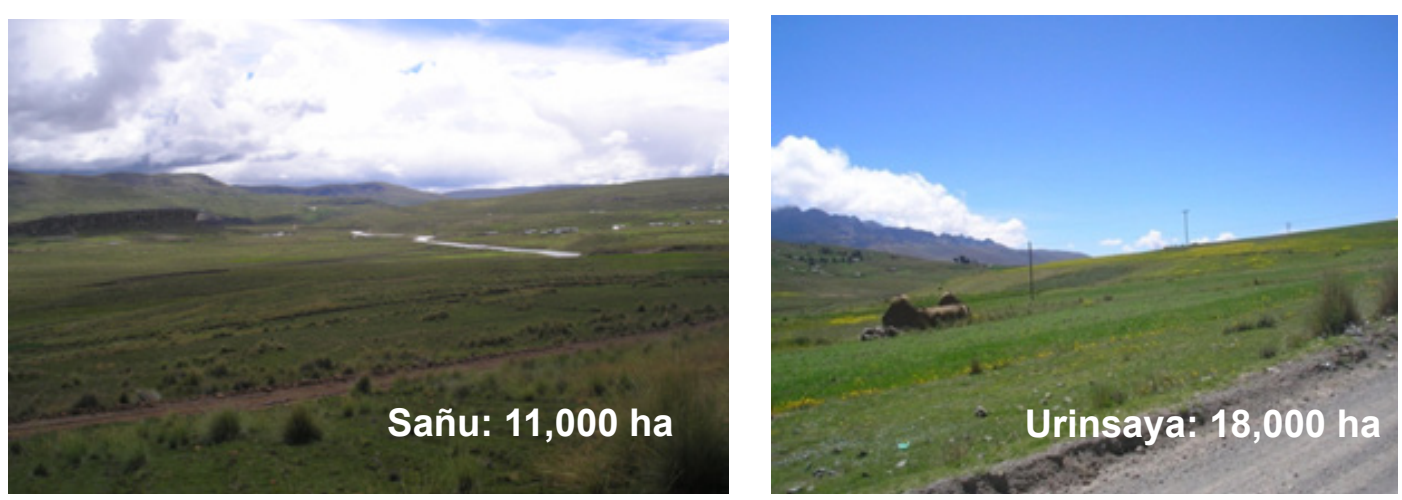

Figura 3. La extensa pradera andina en Espinar puede ser irrigada con tecnología adecuada y hacerla productiva. 

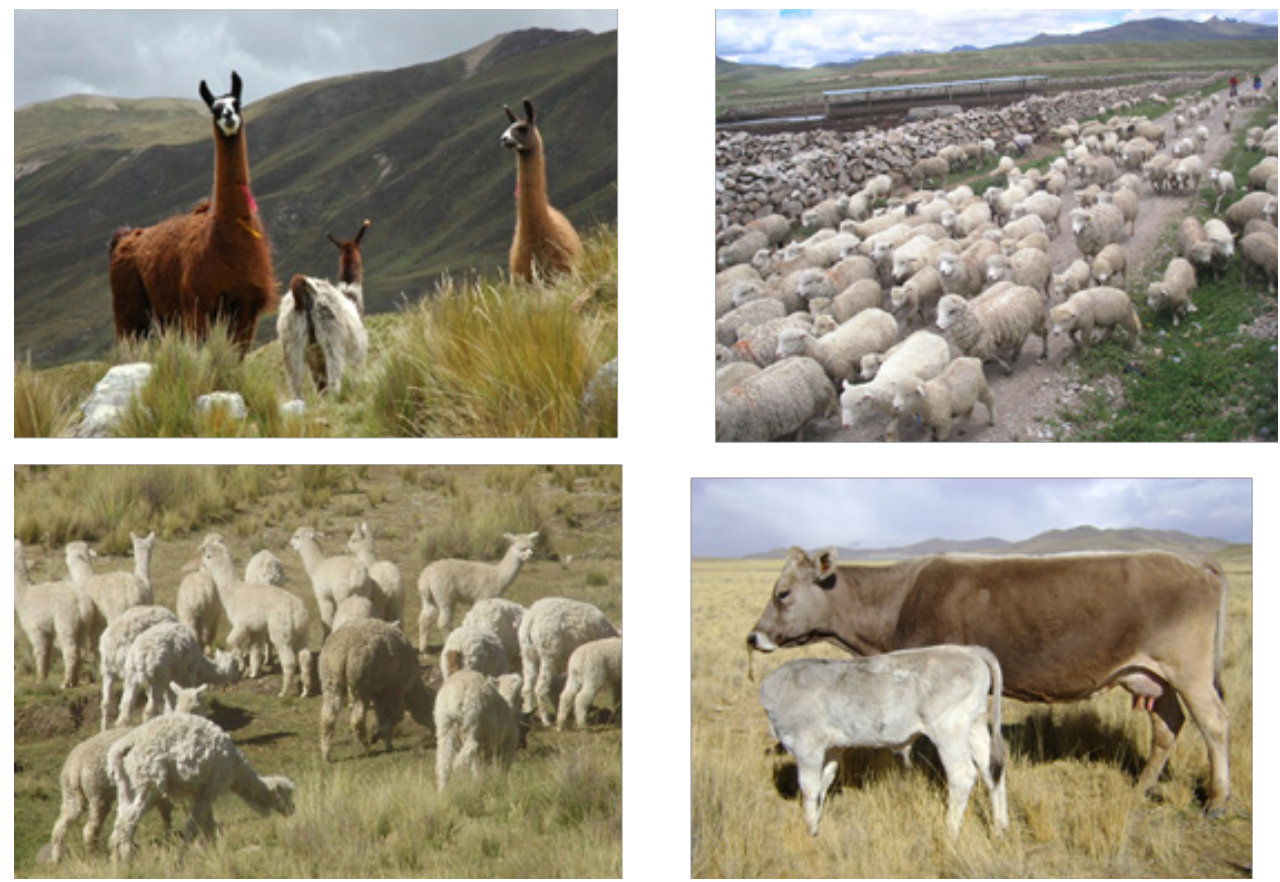

Figura 4. Considerando la aptitud de los suelos para la soportabilidad del ganado, existe ya una distribución en las crianzas. El ganado vacuno se halla en la planicie baja, los ovinos en la zona intermedia y los camélidos sudamericanos en las partes más altas; todos con una biodiversidad interesante de pasturas palatables.
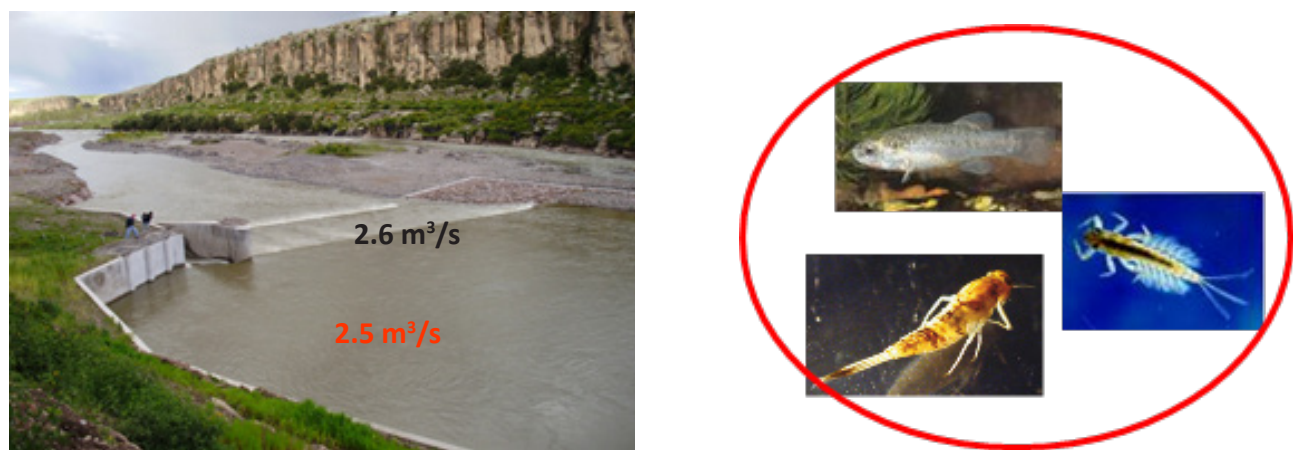

Figuras 5. El caudal ecológico calculado en el 2010, fue de $2.6 \mathrm{~m} 3 / \mathrm{s}$; UNOPS, determinó $2.4 \mathrm{~m} 3 / \mathrm{s}$. Este caudal debe discurrir a lo largo del río. 